\title{
Synthesis, Characterization, and Electrical Properties of Poly(azophenyleneazo-2,4-diamino-1,5-phenylenes)
}

\author{
A. H. Durgaryan, R. H. Arakelyan, N. A. Durgaran, and E. E. Matinyan \\ Department of Chemistry, Yerevan State University, A. Manoogian 1, 0025 Yerevan, Armenia \\ Correspondence should be addressed to A. H. Durgaryan; durgaran@ysu.am
}

Received 15 November 2013; Revised 10 January 2014; Accepted 11 January 2014; Published 23 February 2014

Academic Editor: Yeong-Soon Gal

Copyright ( 2014 A. H. Durgaryan et al. This is an open access article distributed under the Creative Commons Attribution License, which permits unrestricted use, distribution, and reproduction in any medium, provided the original work is properly cited.

Poly(azophenyleneazo-2,4-diamino-1,5-phenylenes) were synthesized via diazotization of $\mathrm{m}$ - and p-phenylenediamine and azocoupling with m-phenylenediamine. It is found that, simultaneously, dihydrobenztriazolic units were formed as a result of cyclization reaction between amino and azo groups located in ortho position to each other. Oxidation of poly(azo-p-phenyleneazo2,4-diamino-1,5-phenylene) was carried out and new polymer with benzotriazolic units in the main polymer chain was obtained. The conductivities of obtained polymers doped with iodine were increased with doping levels increase from $10^{-9}-5 \times 10^{-8} \mathrm{~S} / \mathrm{m}$ to $0,1-0,6 \mathrm{~S} / \mathrm{m}$.

\section{Introduction}

In order to obtain conductive materials with enhanced processability and stability, different alternative methods have been attempted resulting in different degrees of success [1-3]. One of these approaches consists in the synthesis of new polymers with flexible groups incorporated in their backbone. Based on this idea, in the main chain of azo group containing polymers are of particular interest because of their unique photoelectrical characterization [4-6]. However, among electrically active polymers the compounds containing aromatic azo groups are relatively poorly investigated [7-9].

Vesuvin dye is known to be obtained by the reaction of $\mathrm{m}$-phenylenediamine with excess amount of sodium nitrite [10]. As a result, the cross-linked insoluble polymer is formed. This available method has recently been chosen by our group to obtain polyazo-compounds. Electrical conductivity of synthesized polymers increases in the case of doping with iodine to $0.2 \mathrm{~S} \mathrm{~m}^{-1}$ and perchloric acid to $7 \times 10^{-3} \mathrm{~S} \mathrm{~m}^{-1}$. At the action of hydrochloric acid it has been virtually unaffected [11].

The aim of this research is to synthesize polymers containing aromatic azo groups located ortho- to amino groups in the main polymer chain by diazotization reaction of $\mathrm{p}$-(PPDA) and $\mathrm{m}$-(MPDA) phenylenediamine and by subsequent azo coupling of obtained diazonium salts with MPDA and investigate chemical and electrical properties of obtained polymers.

\section{Experimental}

MPDA (bp 358-360 K/0.7 kPa, mp 335.5-336 K) and PPDA (mp 416-418 K) were purified by a vacuum distillation and by sublimation, respectively. Water was used after distillation. All other chemicals were of analytical grade and were used without any further purification.

The IR spectra were recorded on a FT-IR Nicolet Nexus spectrometer ( $\mathrm{KBr}$ pellets). The ${ }^{1} \mathrm{H}$ NMR spectra were taken on a Mercury 300 Varian NMR spectrometer and UV-vis spectra, on a Specord 50 instrument. Electroconductivity of the samples (as pressed pellets) was measured on a Teraohmmeter E6-137 instrument by means of two-contact method.

2.1. The Synthesis of Poly(azo-1,4-phenylene-2,4-diamino-1,5phenylene) (Polymer I). The solution of $1,34 \mathrm{~g}(19,1 \mathrm{mmol})$ sodium nitrite in $7 \mathrm{~mL}$ of water at $268 \mathrm{~K}$ was added slowly to a homogeneous solution of $1 \mathrm{~g}(9.26 \mathrm{mmol})$ PPDA in $14 \mathrm{~mL}$ distilled water, $4,1 \mathrm{~g}$ ice, and $2,1 \mathrm{~mL} 30 \%$ hydrochloric acid. Afterwards, the obtained mixture of diazotizated PPDA was 


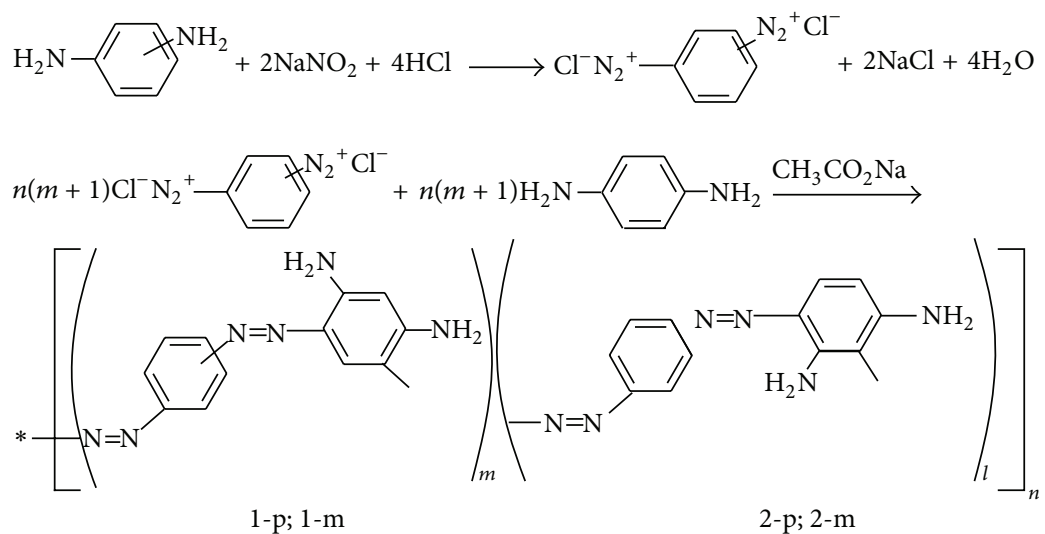

SCHEME 1

slowly added to the solution of $1 \mathrm{~g}(9,26 \mathrm{mmol})$ MPDA and $21 \mathrm{~g}$ sodium acetate in $15,6 \mathrm{~mL}$ of water $(\mathrm{pH}=5)$ at $298 \mathrm{~K}$ and stirred for 3 hours. The reaction mixture was neutralized with sodium hydrocarbonate to $\mathrm{pH}>7$. The solution was filtered off, and the residue was washed with water to neutral reaction. The obtained polymers were dried at room temperature, dissolved in DMF, precipitated, and reprecipitated with water. The polymers were dried in a vacuum at $323-343 \mathrm{~K}(2 \mathrm{kPa})$.

Yield: $1,8 \mathrm{~g}(82 \%)$.

2.2. The Synthesis of Poly(azo-1,3-phenylene-2,4-diamino-1,5phenylene) (Polymer II). The synthesis was carried out analogously to the mentioned-above procedure with reagent qualities $-1.00 \mathrm{~g}(9.26 \mathrm{mmol}) \mathrm{MPDA}, 1.244 \mathrm{~g}$ (19.4 mmol) sodium nitrite, and for azo coupling $1.00 \mathrm{~g}(9.26 \mathrm{mmol}) \mathrm{MPDA}$.

Yield: $1.7 \mathrm{~g}(77.3 \%)$.

2.3. Oxidation of Poly(azo-1,4-phenylene-2,4-diamino-1,5phenylene) (Polymer I) by Copper Sulfate Ammonia Complex [11] (Polymer III). In round-bottom three-necked flask equipped with a mechanical stirrer, a backflow condenser, and a thermometer, $0.32 \mathrm{~g}$ of polymer I was loaded, $25 \mathrm{~mL}$ $50 \%$ ethanol, 4,67 $\mathrm{g}(0,0186 \mathrm{~mol})$ blue copperas, and 7,6 mL $24 \%$ ammonia were added, and the mixture was stirred over 36 hours in a boiling water bath. After that, the reaction mixture was cooled down and filtered. The residue was firstly washed with $4 \%$ ammonia solution till filtrate discoloration and then with acidic acid and water to a neutral medium and absence of $\mathrm{SO}_{4}{ }^{-2}$ ions. The soluble part of polymer was extracted by DMF and precipitated by water. The polymers obtained were dried in vacuum $(323 \mathrm{~K} / 2 \mathrm{kPa})$ and were stored in a desiccator over phosphorus pentoxide.

Yields: $0.09 \mathrm{~g}$ soluble in DMF polymer, $0,16 \mathrm{~g}$ insoluble in DMF polymer. Totally: 0,25 q (76,9\%).

2.4. Doping with Iodine. Iodine solution in $\mathrm{CCl}_{4}$ with determined normality equal to $0.18 \mathrm{~N}$ was added to a weighted sample of fine powdered polymer. This mixture was kept for 2-3 days at room temperature. The precipitate was filtered off and washed twice with a little amount of $\mathrm{CCl}_{4}$ and dried under vacuum $(0.2 \mathrm{kPa})$ in a desiccator with $\mathrm{P}_{2} \mathrm{O}_{5}$. Iodine content in polymers was determined via filtrate titration with $\mathrm{Na}_{2} \mathrm{~S}_{2} \mathrm{O}_{3} 0.1 \mathrm{~N}$ solution and by polymers' weight increase.

The doping level was calculated by the following formula:

$$
Y=\frac{n_{\text {dopant }}(\mathrm{mol})}{n_{\text {repeated structural units }}(\mathrm{mol})} .
$$

Quantity of the structural units was calculated taking into consideration the fact that diazotization and azo coupling reactions proceeded quantitatively.

\section{Results and Discussion}

When the reaction of MPDA with sodium nitrite was carried out simultaneously in a 1:1 molar ratio under the Vesuvin dye synthesis conditions, the resulting diazonium compound coupled in situ with the different positions to unreacted as well as diazotizated amino groups leading directly to the final polymer, which contained a different type of repeat units in its main chain [11]. In the presented work, PPDA and MPDA were first reacted with sodium nitrite in a $1: 2$ molar ratio, and then the compounds obtained after diazotization were coupled with an equivalent amount of MPDA. We expected to obtain the polymer with only one kind of repeating unit in its main chain (Scheme 1).

According to reported literature azo coupling at the 2position of MPDA occurs slightly (1-2\%) [16] and therefore, in a further discussion, we ignore the presence of 2-p and 2-m structural units in obtained polymers. Structural information was gleaned from the IR, ${ }^{1} \mathrm{H}$ NMR, and UV-vis spectra.

${ }^{1} \mathrm{H}$ NMR spectrum (Figure 1) of the polymer in $\left[\mathrm{D}_{6}\right] \mathrm{DMSO}(\delta, \mathrm{mmp})$ features the accordance of integral intensities of amino groups (chem. shifts at 4.95; 5.05; 5.45; $\left.6.43 \mathrm{ppm}\left(\mathrm{NH}_{2}\right), 6.96 \mathrm{ppm}(\mathrm{NH})\right)(4 \mathrm{H})$ with integral intensities of aromatic protons signals: (chem. shifts at 5.89; 5,95; $6,02 ; 6.60 ; 7.32 ; 7.39 ; 7.44 ; 7.70 \mathrm{ppm})(6 \mathrm{H})$. This confirms that the azo-coupling reaction occurs only with the aromatic ring of MPDA. It was expected that the signals of the aromatic protons would appear mainly as singlets. However, doublets are also observed and since the ratio of protons ortho to the azo groups towards protons ortho- to the amino groups was 


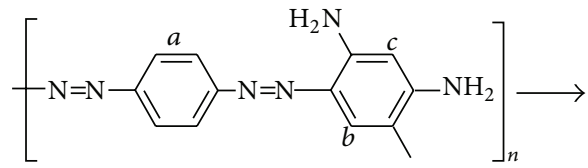

(1)

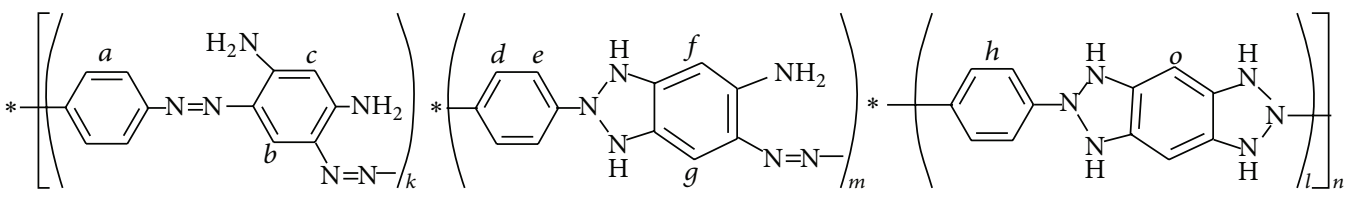

(2)

(3)

(4)

SCHEMe 2

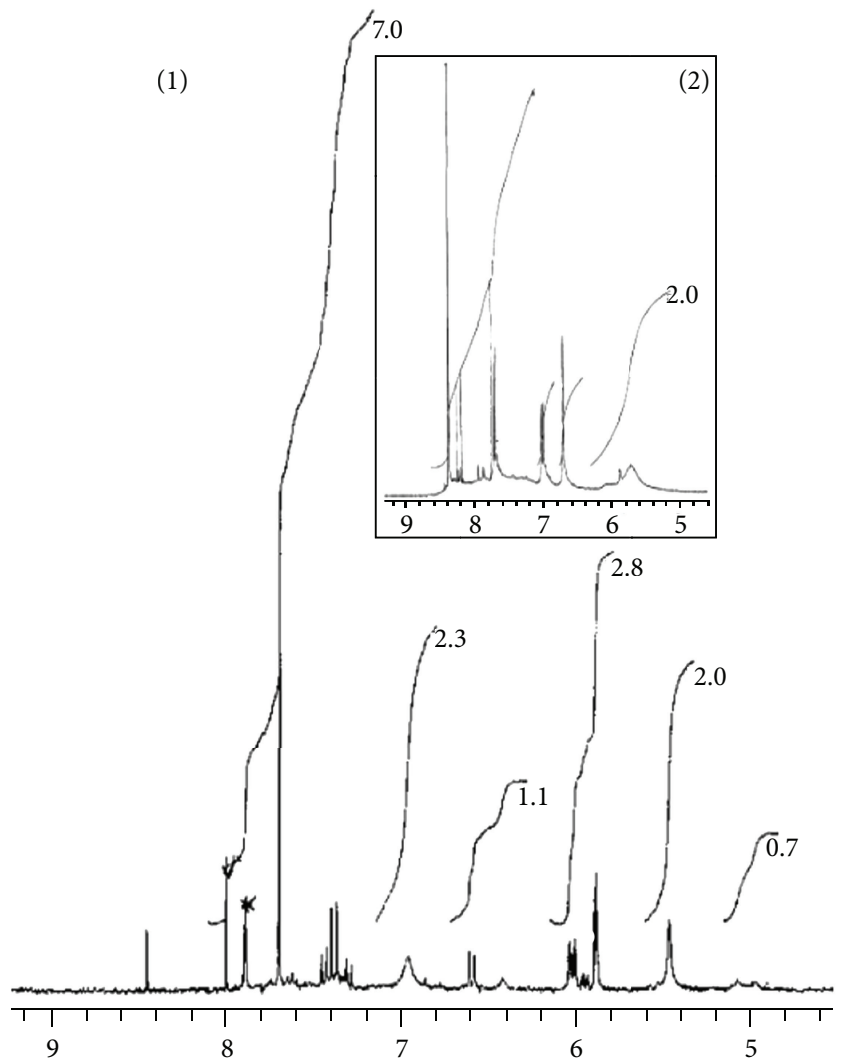

Figure 1: ${ }^{1} \mathrm{H}$ NMR spectra $\left((\mathrm{CD})_{3} \mathrm{SO}, \delta\right.$, ppm) of (1) polymer I; (2) polymer III.

equal to obtained $1.7: 1$ instead of $5: 1$, this can only be due to the cyclization reaction with formation of dihydrobenztriazolic units similar to those represented in Scheme 2.

Four alternative ways were employed to calculate the percentage of cyclic units in the polymers chain from the ${ }^{1} \mathrm{H}$ NMR spectra depicted on Scheme 2. Nearly the same results were obtained from different methods of the calculation of dihydrobenztriazolic structural units in polymer.

Based on the comparison of the area of $\mathrm{NH}_{2}$ proton peak $(4.95 ; 5.05 ; 5.45 ; 6.43 \mathrm{ppm})$, with $\mathrm{NH}$ proton peak $(6.96 \mathrm{ppm})$ on cyclic unites, the percentage of cyclization was calculated to be equal to $38 \%$. Assigning singlets at 7.70 and $8.02 \mathrm{ppm}$ to the protons $a$ and $b$, the molar ratio of structural units $2(k$ on Scheme 2) was calculated through the following equation and it is equal to 0.36 ; that is, the percentage of cyclization was calculated to be equal to $32 \%$ :

$$
k=\left[\frac{(\text { proton area of } a \text { and } b \text { protons } / 5)}{(\text { proton area of } 1 \text { aromatic proton })}\right] \text {. }
$$

Based on integral intensities of protons $d(7.44 d, J=8.7$ and $7.39 d, J=8.8)$ and $e(5.95 d d, J=8.8 ; J=2.4,6.02 d d$, $J=8.8 ; J=2.4,6.60 d, J=8.7)$ the molar ratio of structural units 3 was calculated $-m=0.68$; that is, the percentage of cyclization was calculated to be equal to $34 \%$ :

$$
m=\left[\frac{(\text { proton area of } d \text { and } e \text { protons } / 4)}{(\text { proton area of } 1 \text { aromatic proton })}\right] \text {, }
$$

and based on integral intensities of signals at 7,29 $\mathrm{spm}$, $7,33 s \mathrm{ppm}$ (protons $g(0,68 \mathrm{H})$ ), and at $5.89 \mathrm{~d}$ ppm (protons $c$ and $f(1 \mathrm{H})$ ) cyclization percentage was calculated to be equal to $33 \%$. So, the average value of cyclization was $34 \%$.

According to ${ }^{1} \mathrm{H}$ NMR spectroscopic data $l=0$, it should be noted here that pertinent ${ }^{1} \mathrm{H}$ NMR signals of some known compounds that are useful for the structural determination were compiled in Table 1.

The structure of obtained compound was also confirmed on the basis of IR and UV-vis spectra. IR spectra $\left(\nu, \mathrm{cm}^{-1}\right)$ $-\mathrm{NH}_{2}$ and NH-, 3440, 3357, 3217, 1616, aromatic groups 3094, 1616, 836 (2H), N=N-1504, 1369, =N-C 1326, 1241, N-C 1182, 1133.

The UV-vis spectra of the polymers exhibited absorption maximum at wavelengths 280 and $476 \mathrm{~nm}$, which were assigned to $\pi-\pi^{*}$ transitions of benzenoid moieties connected to amino and azo groups correspondingly. The assignments were made on the basis of the absorptions of the corresponding chromophores in 4-aminoazobenzene in DMSO solution, which were located at 250 and $395 \mathrm{~nm}$.

The reaction of diazotization of MPDA and subsequent coupling with MPDA in many aspects was similar to the reaction discussed above. As a result, polymer with 1-m structural units (polymer II) was obtained (Scheme 1) and according to ${ }^{1} \mathrm{H}$ NMR spectroscopic data, azo coupling was proceeded exceptionally with aromatic ring of MPDA. This assertion was readily apparent from the ratio of integral intensities of 
TABLE 1: Relevant ${ }^{1} \mathrm{H}$ NMR chemical shift data of some protons in model compounds.

\begin{tabular}{|c|c|c|c|c|}
\hline Position of aromatic protons & Model compound & Used solvent & Chemical shift (nm) & Reference \\
\hline ortho- to amino group & Poly(diphenylamine- $4,4^{\prime}$-diyl) & Trifluoroacetic acid & 7.26 & {$[12]$} \\
\hline ortho- to amino group & $\left(\mathrm{C}_{6} \mathrm{H}_{4}(\mathrm{BOC}) \mathrm{NC}_{6} \mathrm{H}_{4} \mathrm{NH}-\right)_{n}$ & THF & 7 & {$[13]$} \\
\hline ortho-protons to azo groups & 4-Aminoazobenzene & & $7.6-7.8$ & {$[14]$} \\
\hline ortho-protons to azo groups & $\begin{array}{l}\text { 7-(4-N,N- } \\
\begin{array}{l}\text { Dihydroxyethylaminophenylazo)-2- } \\
\text { nitro-9-fluorene }\end{array}\end{array}$ & & 8.01 & [15] \\
\hline
\end{tabular}

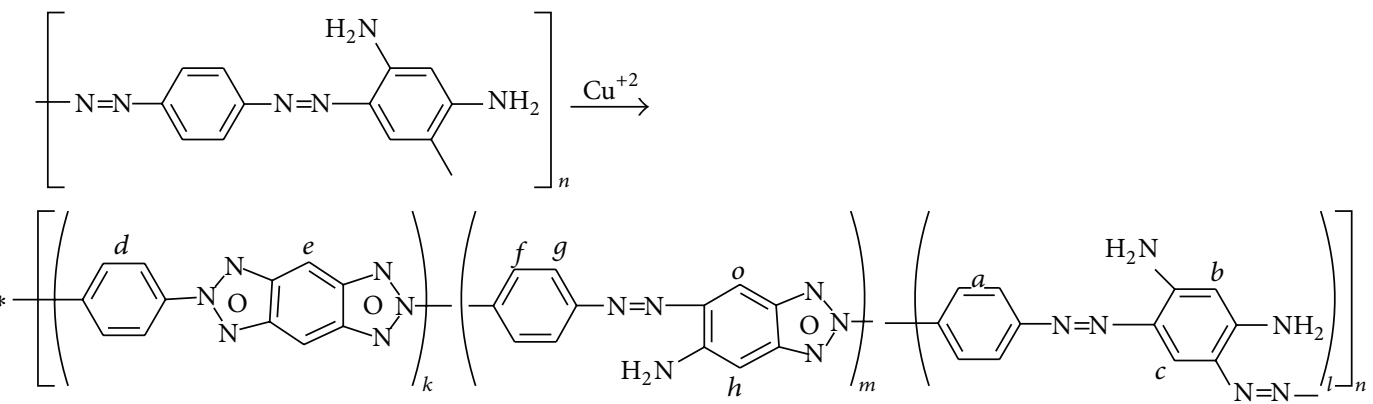

(III)

SCHEME 3

signals due to amino groups $(4 \mathrm{H})$ (chem. shifts at 3.10-3,60; $5.40-5.65 ; 5.85 ; 6.20-6.35 \mathrm{ppm}\left(\mathrm{NH}_{2}\right)$ and at $6.80-7.25 \mathrm{ppm}$ $(\mathrm{NH}))$ to signals due to aromatic ring protons $(6 \mathrm{H})$ (chem. shifts at $5.90 ; 5,95-6,20 ; 7.30-8,00 \mathrm{ppm})$. However, polymer's ${ }^{1} \mathrm{H}$ NMR spectrum was more complicated and only based on peak area of $\mathrm{NH}_{2}$ and $\mathrm{NH}$ protons the percentage of cyclization of amino groups equal to $41 \%$ could be calculated. Another piece of evidence supporting the proposed structure of polymer comes from its UV-vis spectrum (Figure 2 ). The reported UV-vis spectrum $(\lambda, \mathrm{nm}$, in DMSO) reveals the absorbance of $\pi-\pi^{*}$ transitions of benzenoid moieties connected to amino groups at $272 \mathrm{~nm}$ and azophenylene groups at $411,466 \mathrm{~nm}$.

A range of polymer-supported benzotriazoles was screened for use in corrosion inhibition, organic synthesis drug delivery, and so forth $[17,18]$. In terms of synthesizing new polymers that contain benzotriazolic units in main polymer chain, oxidation of poly(azo-p-phenyleneazo-2,4diamino-1,5-phenylene) using blue copperas as oxidizing agent was employed. This reaction is well known for the synthesis of low molecular weight benzotriazoles [16].

Comparison of UV-vis spectra of obtained oxidized polymer III (in DMSO $c=1,08 \times 10^{-2} \mathrm{~g} / \mathrm{L}$ ) and initial polymer I (in DMSO $c=1,1 \times 10^{-2} \mathrm{~g} / \mathrm{L}$ ) (Figure 2) revealed the decrease in peak intensity of phenyleneamino groups at $273 \mathrm{~nm}\left(y=0.5588, \varepsilon=51.74 \mathrm{~L} \cdot \mathrm{g}^{-1} \cdot \mathrm{cm}^{-1}\right)$, the peak with low intensity of initial polymer at $476 \mathrm{~nm}(y=0.25799, \varepsilon=$ $99.7 \mathrm{~L} \cdot \mathrm{g}^{-1} \cdot \mathrm{cm}^{-1}$ ) (appears as a shoulder), and the appearance of new absorbance at $408 \mathrm{~nm}(y=0.579, \varepsilon=$ $53.6 \mathrm{~L} \cdot \mathrm{g}^{-1} \cdot \mathrm{cm}^{-1}$ ) (characteristic for benzotriazolic units). On the bases of absorbance intensities at $476 \mathrm{~nm}$ of both initial $(y=1.097)$ and oxidized polymers, it can be calculated that $24 \%$ of structural units of initial polymer remains unchanged.

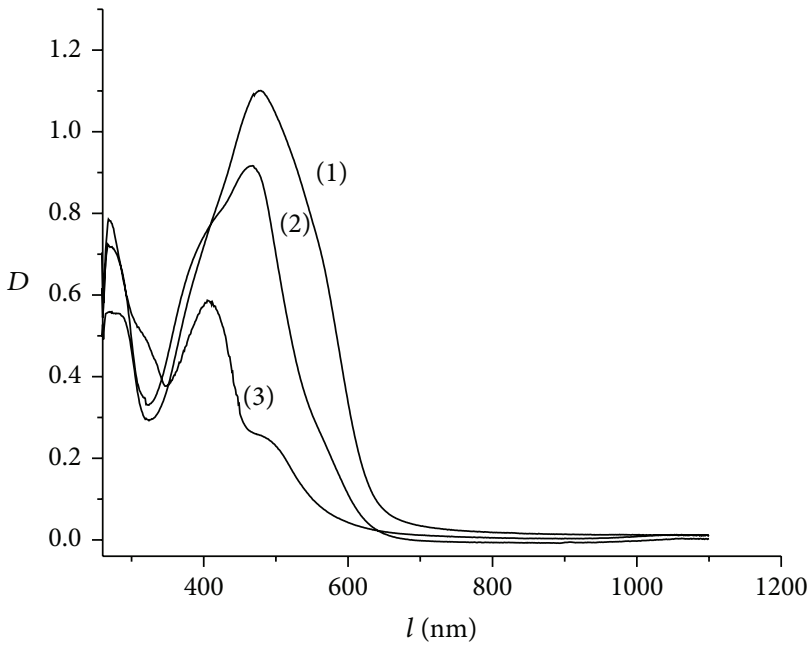

FIgURE 2: UV spectra $(\lambda, \mathrm{nm})$ of (1) polymer I; (2) polymer II; (3) oxidized polymer III.

The $\mathrm{H}^{1}$ NMR result of oxidized polymer strongly differs from that of initial polymers. The spectrum shown in Figure 1(2) revealed the presence of: $e$ and $o$ protons (8,38 $s \mathrm{ppm}), g$ and probably $a$ protons $(7.75 d \mathrm{ppm} ; J=9,13 \mathrm{~Hz}$ ), $a$ protons (5.88 $s$ ppm), $f$ protons $(7.0 d \mathrm{ppm} ; J=9,13 \mathrm{~Hz}), d$ protons (6.65 $s \mathrm{ppm}$ ), and $\mathrm{NH}_{2}$ (broden signal, 5.5-6.2 ppm).

Taking into account the intensities of $f, d$, and $\mathrm{NH}_{2}$ protons the values $k, m$, and $l$ in the formula (III) (Scheme 3 ) have been calculated to be equal to $k=0.27, m=0.50$, and $l=0.23$. These calculations confirm the conclusion from UV studies-the cyclization percent is 24 . 


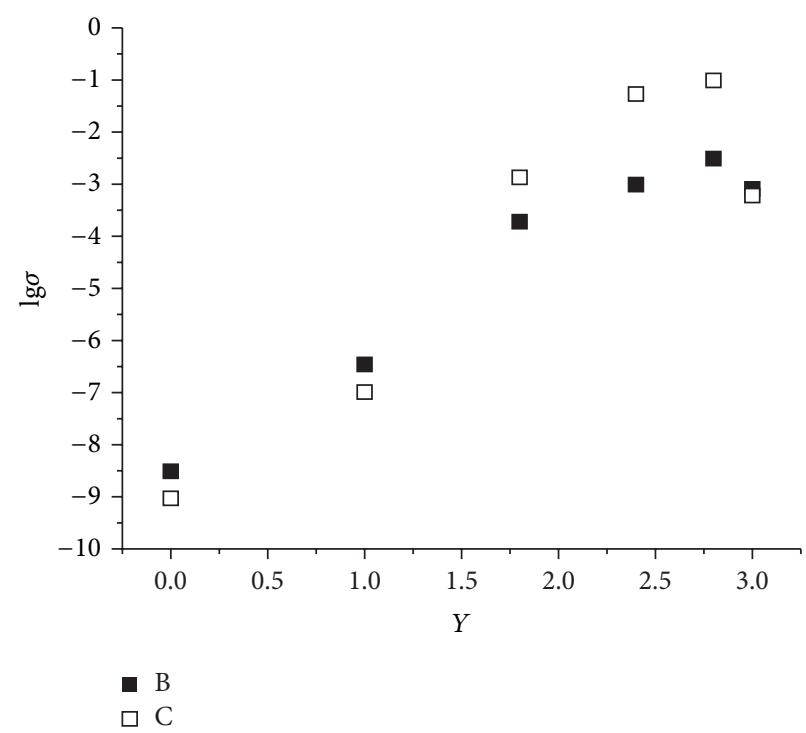

(a)

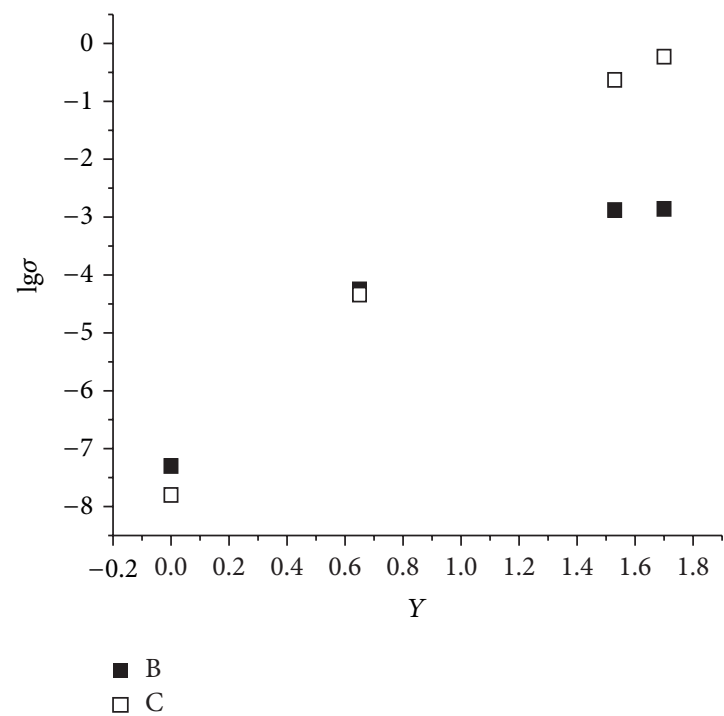

(b)

FIGURE 3: Plot of electric conductivities ( $\lg \sigma ; \mathrm{S} / \mathrm{m}$ ) as a function of iodine doping level of (a) polymer I and (b) polymer III. C-conductivities of the same samples after heating to $345 \mathrm{~K}$ and cooling, measured at room temperature.

The synthesized polymers I and III were doped with iodine and electroconductivities for the doped and undoped polymers were determined. Room temperature electric conductivities of I and III virgin polymers were equal to $10^{-9}$ and $5 \times 10^{-8} \mathrm{~S} / \mathrm{m}$, respectively. Conductivity increases steadily with increased doping levels in the considered range and attains values of $0,1 \mathrm{~S} / \mathrm{m}$, when the doping level was 2.5 , (polymer I) and $0,6 \mathrm{~S} / \mathrm{m}$ for polymer (III) when the doping level was 1.6 (Figure 3). These values are comparable to those determined for polymer obtained from MPDA by in situ diazotization and azo coupling $\left(2 \times 10^{-3} \mathrm{~S} / \mathrm{m}\right)$ [11], iodine-doped PANi $\left(1.83 \times 10^{-1} \mathrm{~S} / \mathrm{m}\right)$ [19], and poly(azo-p-phenylene) $(1 \times$ $\left.10^{-2} \mathrm{~S} / \mathrm{m}\right)[8,9]$.

After heating to $345 \mathrm{~K}$, electric conductivity of polymer, doped with iodine and containing more than $0.8 \mathrm{~mol}$ of iodine per one mol of azo amino phenylene units, increases in some cases by 2-3 orders of magnitude when measured additionally at room temperature (Figure 3 ). Evidently, this can be caused by morphological changes in the structure of the doped polymer.

Fluorescence spectra were recorded for the solution of polymer I in DMSO $c=1.1 \times 10^{-2} \mathrm{~g} / \mathrm{L}$ in a Cary Eclipse spectrometer (Figure 4). We have chosen $290 \mathrm{~nm}$ as the exciting wavelength due to the peak in the excitation scan. The resulting emission scan contains two peaks, one small at $410 \mathrm{~nm}$ and a high one at $340 \mathrm{~nm}$.

\section{Conclusion}

It is the first time poly(azo-m(p)-phenyleneazo-2,4-diamino1,5-phenylenes) has been synthesized by the diazotization of $\mathrm{p}$ - and $\mathrm{m}$-phenylenediamines and azo coupling with $\mathrm{m}$ phenylenediamine. Simultaneous reaction between azo and amino groups proceeded via formation of dihydrotriazolic

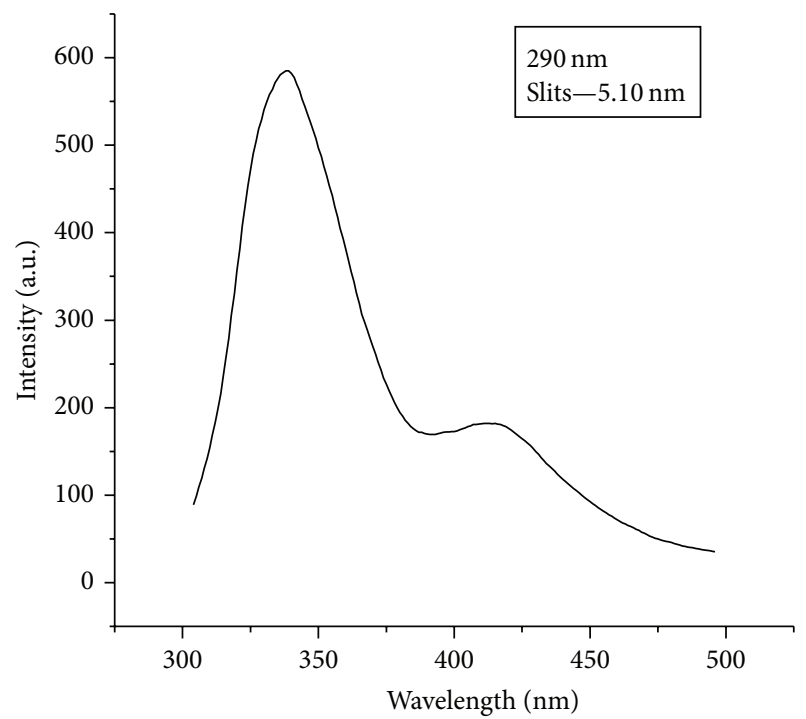

FIGURE 4: Fluorescence emission spectra of the polymer I (in DMSO, $\left.c=1.1 \times 10^{-2} \mathrm{~g} \cdot \mathrm{L}^{-1}\right)$.

cycles has been established. For the first time new polymer containing triazolobenzolic units in the main polymer chain has been prepared by the oxidation of obtained poly(azo-pphenyleneazo-2,4-diamino-1,5-phenylene). It has been found that conductivities of obtained polymers increase with doping level increase up to $0,1 \mathrm{~S} / \mathrm{m}$ for initial and to $0,6 \mathrm{~S} / \mathrm{m}$ for oxidized polymers.

\section{Conflict of Interests}

The authors declare that there is no conflict of interests regarding the publication of this paper. 


\section{References}

[1] T. A. Skorheim, R. L. Elsenbaumer, and J. R. Reynolds, Eds., Handbook of Conducting Polymers, Marcel Dekker Inc., New York, NY, USA, 2nd edition, 1998.

[2] X. G. Li, M. R. Huang, W. Duan, and Y. L. Yang, "Novel multifunctional polymers from aromatic diamines by oxidative polymerizations," Chemical Reviews, vol. 102, no. 9, pp. 2925-3030, 2002.

[3] A. H. Durgaryan, N. A. Durgaryan, R. H. Arakelyan, and E. E. Matinyan, "Syntheses and investigation of polymers containing 1-triazene-1,3-diyl and 1,4-phenylene group," Synthetic Metals, vol. 160, no. 1-2, pp. 180-186, 2010.

[4] D. Timpu, V. Barboiu, A. Airinei, and E. Rusu, "Transparent layers of azo-conjugated polymers: preparation and opto-electrical properties," Journal of Optoelectronics and Advanced Materials, vol. 2, no. 5, pp. 531-535, 2000.

[5] Y. Chen, Q. Gong, F. Wang, B. Zhang, and Z. Chen, "Synthesis and characterization of photorefractive materials based on polymers containing photoconductors and nonlinear chromophores," Materials Letters, vol. 57, no. 28, pp. 4372-4377, 2003.

[6] H. S. Nalwa, Ed., Handbook of Organic Conductive Molecules and Polymers, Wiley, New York, NY, USA, 1997.

[7] D. M. Carlton, D. K. McCarthy, and R. H. Genz, "The effect of structure on the electrical conductivity of organic compounds. Polyazophenylenes," Journal of Physical Chemistry, vol. 68, no. 9, pp. 2661-2665, 1964.

[8] F. Barbarin, J. P. Blanc, M. Dugay, C. Fabre, and C. Maleysson, "Conductivity and E.S.R. investigations of doping and dedoping in poly-p-azophenylene and poly-p-phenylene azomethine," Synthetic Metals, vol. 10, no. 1, pp. 71-78, 1984.

[9] T. Kuo and H. K. Hall Jr., "Synthesis and electrical properties of poly(p-azoarylene) films," Synthetic Metals, vol. 22, no. 2, pp. 115-120, 1987.

[10] Beilsteins Handbuch der Organischen Chemie, vol. 16, Springer, Berlin, Germany, 4th edition, 1991.

[11] A. A. Durgaryan, N. A. Durgaryan, and R. A. Arakelyan, "Synthesis of polymers containing azo groups in the main chain from $m$-phenylenediamine: study of doping," Russian Journal of General Chemistry, vol. 80, no. 5, pp. 976-981, 2010.

[12] T. Yamamoto, S. B. Kim, and T. Maruyama, "Preparation of poly(diphenylamine-4,4/-diyl) and a related polymer by organometallic polycondensation and their properties," Chemistry Letters, no. 6, pp. 413-414, 1996.

[13] X. X. Zhang, J. P. Sadighi, T. W. Mackewitz, and S. L. Buchwald, "Efficient synthesis of well-defined, high molecular weight, and processible polyanilines under mild conditions via palladiumcatalyzed amination," Journal of the American Chemical Society, vol. 122, no. 31, pp. 7606-7607, 2000.

[14] SDBSWeb, National Institute of Advanced Industrial Science and Technology, http://riodb01.ibase.aist.go.jp/sdbs/ .

[15] F. Cariati, U. Caruso, R. Centore et al., "Optical second order nonlinearities in new chromophores obtained by selective mono-reduction of dinitro precursors," Optical Materials, vol. 27, no. 1, pp. 91-97, 2004.

[16] M. P. Schmidt and A. Hagenbocker, "Zur Kenntnis der Pseudoazimide. (2. Mitteilung)," Berichte der Deutschen Chemischen Gesellschaft, vol. 54, no. 9, pp. 2201-2207, 1921.

[17] H. Y. Wang, J. G. Jiang, L. Y. Ma, and Y. L. Pang, "Syntheses of molecularly imprinted polymers and their molecular recognition study for benzotriazole," Reactive and Functional Polymers, vol. 66, no. 10, pp. 1081-1086, 2006.
[18] S. Tamil Selvi, V. Raman, and N. Rajendran, "Corrosion inhibition of mild steel by benzotriazole derivatives in acidic medium," Journal of Applied Electrochemistry, vol. 33, no. 12, pp. 1175-1182, 2003.

[19] X. R. Zeng and T. M. Ko, "Structure-conductivity relationships of iodine-doped polyaniline," Journal of Polymer Science B, vol. 35, no. 13, pp. 1993-2001, 1997. 

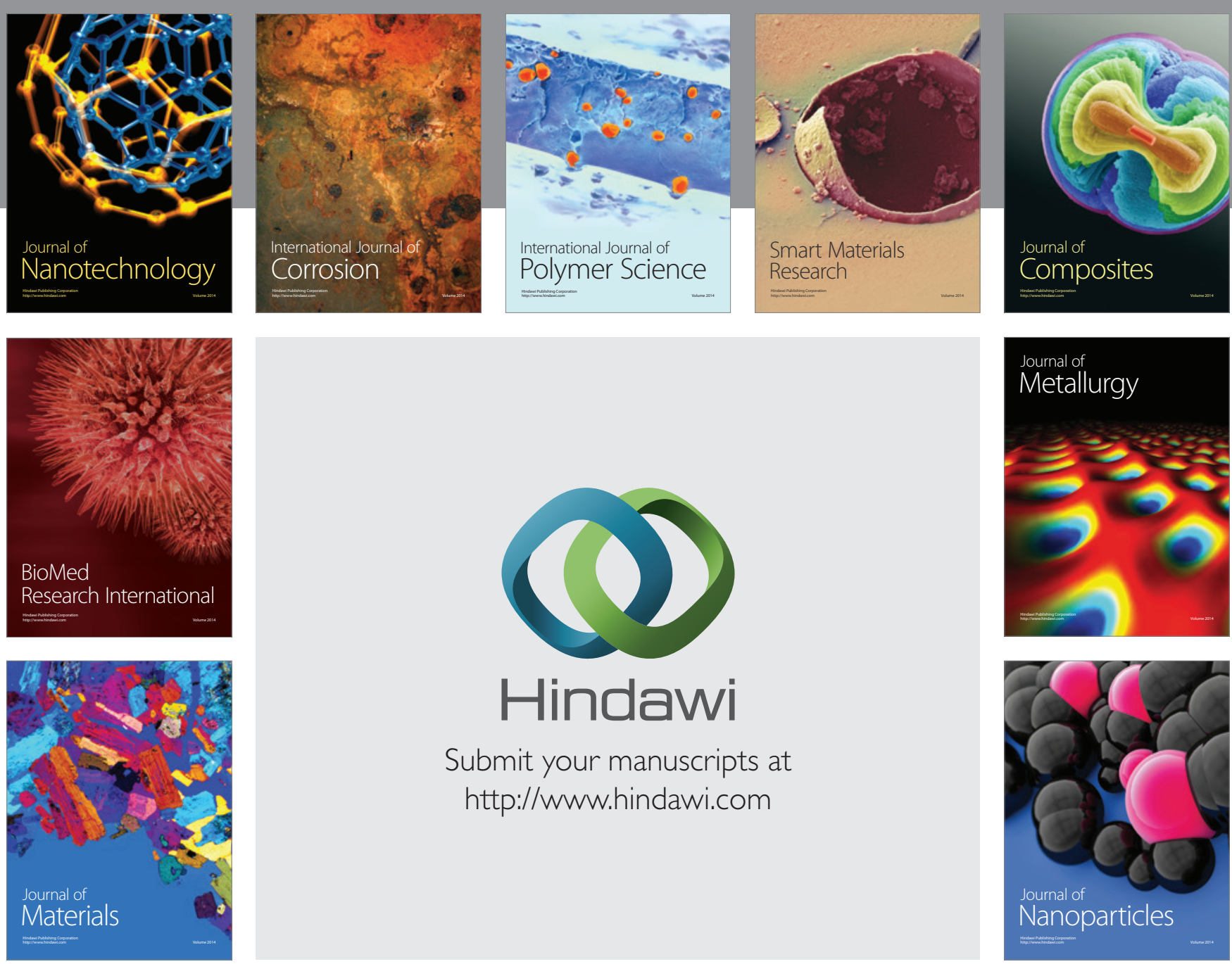

Submit your manuscripts at http://www.hindawi.com
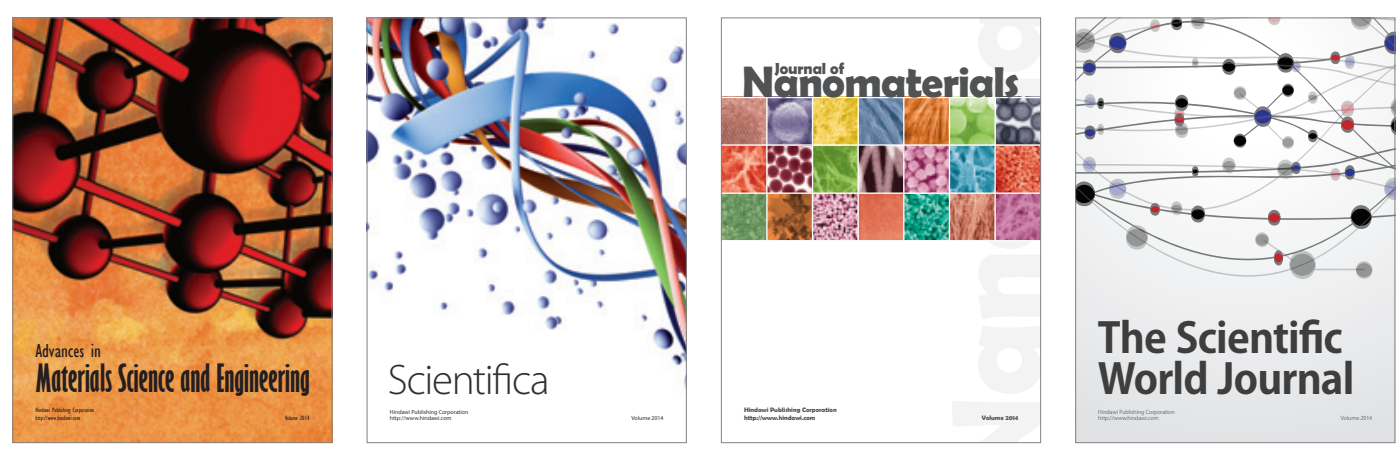

\section{The Scientific World Journal}
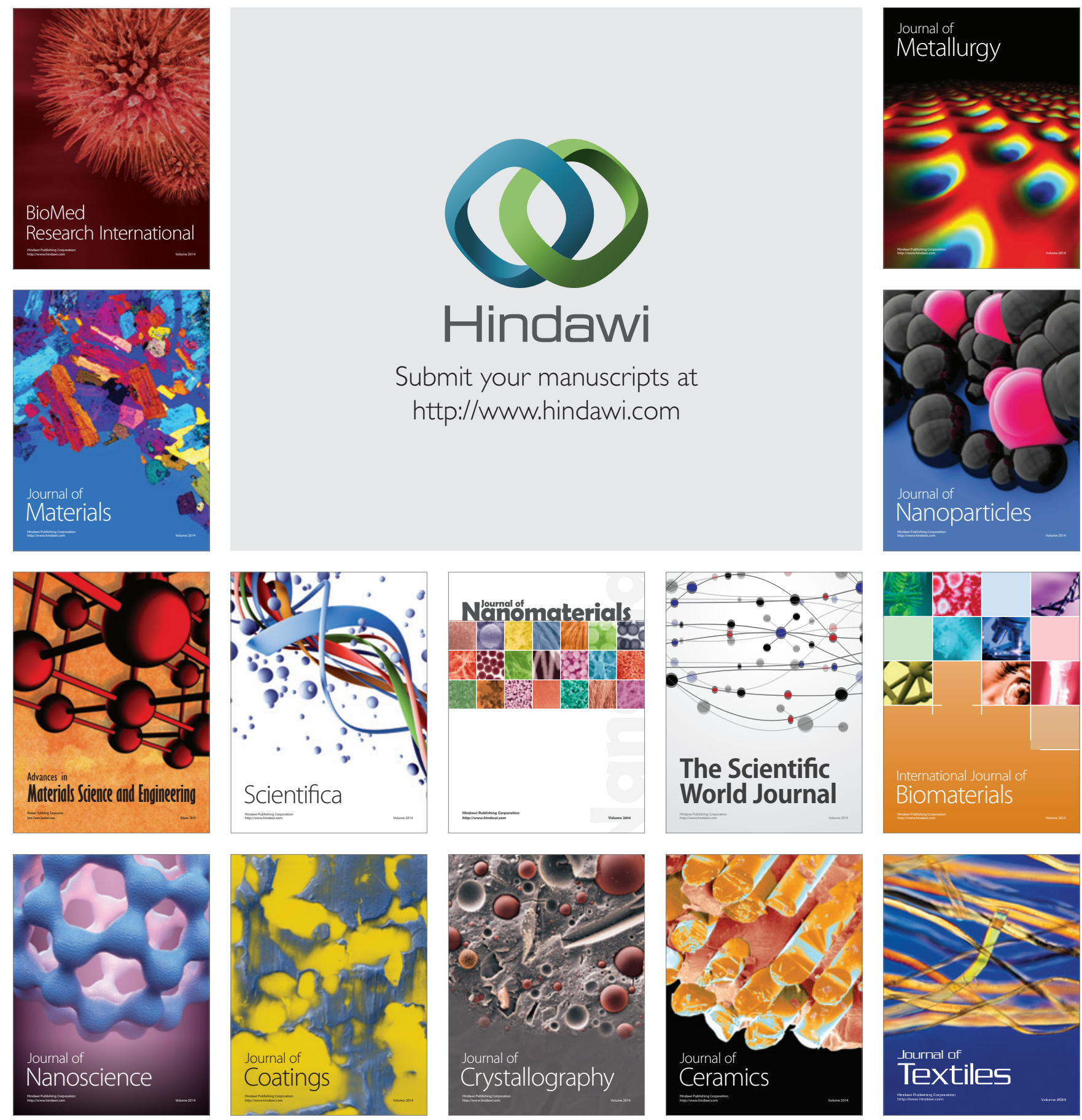